\title{
Incidence of American Tegumentary Leishmaniosis in the Municipality of Rondoland - MT in the Period 2010 to 2018
}

\author{
Gleison Faria ${ }^{1, ~ *, ~ G r a c i e l y ~ d o s ~ S a n t o s ~ d a ~ L u z ~}{ }^{1}$, Thais Antunes Betin ${ }^{2}$ \\ ${ }^{1}$ Nursing Course of the Institution of Higher Education, Faculty of Biomedical Sciences, Cacoal-Rondonia, Brazil \\ ${ }^{2}$ Institution of Higher Education, Faculty of Biomedical Sciences of Cacoal, Rondonia, Brazil
}

Email address:

gleisonfaria@hotmail.com (G. Faria)

${ }^{*}$ Corresponding author

\section{To cite this article:}

Gleison Faria, Graciely dos Santos da Luz, Thais Antunes Betin. Incidence of American Tegumentary Leishmaniosis in the Municipality of Rondoland - MT in the Period 2010 to 2018. International Journal of Chinese Medicine. Vol. 3, No. 3, 2019, pp. 34-40.

doi: $10.11648 / j . i j c m .20190303 .11$

Received: April 21, 2019; Accepted: July 9, 2019; Published: July 23, 2019

\begin{abstract}
American tegumentary leishmaniasis (ACL) is an infectious, non-contagious disease that causes ulcers on the skin and mucous membranes. The disease is caused by protozoa of the genus Leishmania. The objective of the research was to verify the incidence of American cutaneous leishmaniasis in the municipality of Rondolândia - MT from 2010 to 2018. The methodology and of the transversal, documental, descriptive and quantitative type, the information will be obtained from the analysis of epidemiological data provided by health surveillance of the municipality of Rondolândia - MT, who were attended at the Hueverton basic health unit Bruno da Silva Rabelo, who will be separated through a questionnaire carried out by the researchers themselves containing 4 basic questions based on the SINAN compulsory notification form. It was verified that 40 cases of American tegumentary leishmaniasis were reported in the municipality of Rondolândia-MT between 2010 and 2018, $90.0 \%$ being male and $10.0 \%$ female in the age group with the highest incidence 18 to 59 years of age to $85.0 \%$ of the reports and $45.0 \%$ of the patients were brown, $95.0 \%$ of the patients presented skin lesions and were classified as new cases. The patients' diagnoses were confirmed by $85.0 \%$ laboratory, $90.0 \%$ of the patients were treated with pentavalent antimonial and $90.0 \%$ of the patients were from the rural area of the municipality of Rondolândia-MT. It is concluded that the incidence of cases of American tegumentary Leishmaniasis in the municipality of Rondolândia-MT has been increasing over the years, that is, approximately 1 case per 100 inhabitants, thus, the annual average of these cases corresponding to 5 cases of the annual disease. An urgent action is required by the health surveillance department of the municipality to carry out disease control, since if it continues without prevention in the municipality, this annual index may suffer a great increase over the years.
\end{abstract}

Keywords: Investigation, Epidemiology, Treatment

\section{Introduction}

Infectious disease, however, non-contagious, caused by parasites of the genus Leishmania. The parasites live and multiply inside the cells that are part of the individual's defense system, called macrophages. There are two types of leishmaniasis: cutaneous or cutaneous leishmaniasis and visceral leishmaniasis or kalazar [1].

Cutaneous leishmaniasis is characterized by skin wounds that are most often located in the body's uncovered parts. Suddenly, sores on the mucous membranes of the nose, mouth, and throat may appear. Visceral leishmaniasis is a systemic disease, therefore, it affects several internal organs, mainly the liver, the spleen and the bone marrow. This type of leishmaniasis affects mainly children up to ten years of age; after this age it becomes less frequent. It is a disease of long evolution, lasting for a few months or even exceeding the period of one year [1].

In the Americas, 11 dermotropic Leishmania species that cause human disease and 8 species described only in animals are currently recognized. However, in Brazil, 7 species have already been identified, 6 of the subgenus Viannia and 1 of the subgenus Leishmania [2].

In Brazil, American tegumentary leishmaniasis, popularly known as "bauru ulcer" or "bruised wound", is transmitted by 
the mosquitoes of the genus Lutzomyia, known as straw mosquitoes, and the treatment is done under the guidance of the dermatologist. of injectable drugs, known as pentavalent Antimonyals [3].

From 2001 to 2014, a total of 797,849 new cases of cutaneous and mucosal leishmaniasis were reported to PAHO / WHO with an annual average of 56,989 distributed in 17 of the 18 endemic countries of the Americas. A stable regional trend is observed, however, analyzing the periods individually, there is an increase in cases up to 2005 . A total of $75 \%$ of the detected cases were reported by Brazil $(20,418)$ [4].

Tegumentary leishmaniasis (LT) is therefore justified throughout Brazil, with a record of autochthonous cases in all units of the federation (UF) since 2003, especially in wild and rural areas. It is considered to be a neglected disease because it affects mainly low-income populations $[5,6]$.

The general objective of the research was to verify the incidence of American cutaneous leishmaniasis in the municipality of Rondolândia-MT from 2010 to 2018 .

\section{Methodology}

The present work presented as a retrospective, transverse, descriptive documentary with a quantitative approach [7]. The research was conducted in the municipality of Rondolândia-MT, had as a data collection instrument a semi-structured questionnaire of 04 questions of multiple choices that were extracted from the disease notification form itself, addressing inclusion criteria with the following variables: Identify the profile of the age, sex, color, schooling, area of occurrence and treatment indicated, with the purpose of directing the collection of data, which extracted the secondary information from the database of the information system of notification diseases - SINAN which were provided by the municipal health department of the municipality epidemiology sector by the responsible server, made available to the researchers in the form of spreadsheets in Microsoft Excel ${ }^{\circledR}[8]$.

Evaluated by the ethics and research committee (CEP) of the Faculty of biological sciences of Cacoal-RO (FACIMED by its approval received the number of the opinion substantiated $\mathrm{n}^{\mathrm{o}} 2.882 .724$.

The survey began in August and September 2018, and obtained a sample of 40 reports of the disease. There was no exclusion of notification, because before receiving the data, the data needed for the survey were sent via e-mail to the epidemiology department (10 to $14,18,21,33,39,40,42$ and 47) of the notification form, thus facilitating the filtering of the SINAN database for the epidemiology officer, who after being made available as requested to the researchers, does not listen to costs or remuneration for the data obtained and no exposure of the integrity of the notified patients, it was not necessary to use the informed consent form - TCLE because the data were secondary and thus requested the exemption of the same to the CEP.

They had as exclusion criterion all the notifications that did not have necessary information for the study, not belonging to the municipality of Rondolândia-MT or the cases not closed in the period.

\section{Results}

There was a sample of 40 confirmed cases of American cutaneous leishmaniasis in the municipality of Rondolândia-MT, being $100 \%$ of the cases belonging to the rural area of the municipality (Table 1). The reported data were collected and tabulated through information provided by the municipal health department of the municipality through the statistical sector that were extracted by the SINAN database [8].

Distribution of cases of American cutaneous leishmaniasis, according to the year, in the municipality of RondolândiaMato Grosso State. Brazil, 2010 to 2018.

Table 1. Notifications of American tegumentary leishmaniasis by year of occurrence - Rondolândia-MT - 2010 to 2018.

\begin{tabular}{lllll}
\hline \multirow{2}{*}{ ANO } & \multicolumn{4}{l}{ LOCALIDADE } \\
\cline { 2 - 5 } & URBAN & $\mathbf{\%}$ & RURAL & \% \\
\hline 2010 & - & 0 & 03 & 7,50 \\
2011 & - & 0 & 01 & 2,50 \\
2012 & - & 0 & 03 & 7,50 \\
2013 & - & 0 & 07 & 17,50 \\
2014 & - & 0 & 08 & 20,00 \\
2015 & - & 0 & 01 & 2,50 \\
2016 & - & 0 & 03 & 7,50 \\
2017 & - & 0 & 03 & 7,50 \\
2018 & - & 0 & 10 & 25,00 \\
TOTAL & & 0 & 40 & 100 \\
\hline
\end{tabular}

Source: SINAN/SEMUSA/MS, 2010-2018, Rondolândia - MT.

As shown in table 1, 2014 had a higher incidence of American tegumentary leishmaniasis with $20.00 \%(\mathrm{n}=8)$ and followed the year 2013 with $17.50 \%(n=7), 2018$ with $25.00 \%$ $(\mathrm{n}=10)$ and in the previous years 2010, 2012, 2016 and 2017 with $7.50 \%(n=3)$ and 2011 and 2015 with $2.50 \%(n=1)$.

Table 2 shows the socio-demographic profile of the patients reported with tegumentary leishmaniasis america in the municipality, with $90.00 \%(\mathrm{n}=36)$ being males and $10.00 \%$ $(n=4)$ females. The age groups of the patients correspond to $<18$ years (under 18 years) with $10.00 \%(\mathrm{n}=4)$ and $>18$ years $<59$ years $85.00 \%(\mathrm{n}=34)$ and $>60$ years $5.00 \%(\mathrm{n}=2)$. Regarding the schooling of the reported victims, it describes that $2.50 \%(\mathrm{n}=1)$ are illiterate or have a complete 4 th grade, $5.00 \%(n=6)$ have incomplete 5 th to 6 th grade, complete primary education, Incomplete secondary school, $7.50 \%(\mathrm{n}=$ 3) 1 st to 4 th grade incomplete and $67.50 \%(n=27)$ of this information was ignored by the notifier. In relation to race / color of the victims 40,00 $(\mathrm{n}=16)$ white, $45,0 \%(\mathrm{n}=18)$ brown, 7,50\% $(\mathrm{n}=3)$ black, $5,00 \% 2.50 \%(\mathrm{n}=1)$ were ignored.

Characteristics of cases of American cutaneous leishmaniasis in the municipality of Rondolândia, State of Mato Grosso. Brazil, 2010 to 2018. 
Table 2. Demographic profile of patients diagnosed with American cutaneous leishmaniasis in the municipality of Rondolândia, State of Mato Grosso. Brazil, 2010 to 2018

\begin{tabular}{|c|c|c|c|}
\hline CLINICAL DATA & & $\mathbf{N}$ & $\%$ \\
\hline \multirow{3}{*}{ SEX } & Male & 36 & 90,00 \\
\hline & Female & 4 & 10,00 \\
\hline & TOTAL & 40 & 100 \\
\hline \multirow{5}{*}{ Age group (age) } & $<18$ & 4 & 10,00 \\
\hline & $18-59$ & 34 & 85,00 \\
\hline & $>60$ & 2 & 5,00 \\
\hline & TOTAL & 40 & 100 \\
\hline & Illiterate & 1 & 2,50 \\
\hline \multirow{7}{*}{ Schooling (years of study completed) } & 1 st to 4 th grade incomplete & 3 & 7,50 \\
\hline & 4th complete series & 1 & 2,50 \\
\hline & 5th to 6 th grade incomplete & 2 & 5,00 \\
\hline & Complete primary education & 2 & 5,00 \\
\hline & Complete high school & 2 & 5,00 \\
\hline & Incomplete high school & 2 & 5,00 \\
\hline & Ignored & 27 & 67,50 \\
\hline \multirow{7}{*}{ Color } & TOTAL & 40 & 100 \\
\hline & White & 16 & 40,00 \\
\hline & black & 3 & 7,50 \\
\hline & brown & 18 & 45,00 \\
\hline & Indigenous & 2 & 5,00 \\
\hline & Ignored & 1 & 2,50 \\
\hline & TOTAL & 40 & 100 \\
\hline
\end{tabular}

Source: SINAN/SEMUSA/MS, 2010-2018 - Rondolândia-MT

Based on the table 3 that corresponds to the clinical data of the patients reported with American tegumentary leishmaniasis, 95.00\% $(\mathrm{n}=38)$ patients had a cutaneous lesion and $5.00 \%$ non $(n=2)$ presented lesion cutaneous lesions, but presented mucosal lesion also corresponding to $5.00 \%(n=2) .95 \%(n=38)$ of the reports were registered as new cases and $5.00 \%(n=2)$ recurrence, on the criterion of confirmation of symptoms $85.00 \%(\mathrm{n}=(\mathrm{N}=36)$ were used for laboratory treatment and $15.00(n=6)$ were clinical / Epidemiological, 90.00\% $(n=36)$ were used antimonial pentavalent and $10.00 \%(\mathrm{n}=4)$ which were not reported in the notification form.

Clinical data of patients reported with American cutaneous leishmaniasis in the municipality of Rondolândia-MT between 2010 and 2018 .

Table 3. Complementary data of cases of American cutaneous leishmaniasis in the municipality of Rondolândia, State of Mato Grosso. Brazil, 2010 to 2018.

\begin{tabular}{|c|c|c|c|}
\hline CLINICAL DATA & & $\mathbf{N}$ & $\%$ \\
\hline \multirow{3}{*}{ Skin lesion } & Yes & 38 & 95,00 \\
\hline & No & 2 & 5,00 \\
\hline & TOTAL & 40 & 100 \\
\hline \multirow{4}{*}{ Mucosal lesion } & Yes & 2 & 5,00 \\
\hline & No & 38 & 95,00 \\
\hline & TOTAL & 40 & 100 \\
\hline & New case & 38 & 95,00 \\
\hline \multirow{3}{*}{ Case classification } & Download & 0 & 0 \\
\hline & Ignored & 0 & 0 \\
\hline & TOTAL & 40 & 100 \\
\hline \multirow{3}{*}{ confirmation criterion } & Laboratory & 34 & 85,00 \\
\hline & Clinical / Epidemiological & 6 & 15,00 \\
\hline & TOTAL & 40 & 100 \\
\hline Treatment & Pentavalent Antimony & 36 & 90,00 \\
\hline \multirow{3}{*}{ Place of occurrence } & Urban & 0 & 0 \\
\hline & Rural & 40 & 100 \\
\hline & TOTAL & 40 & 100 \\
\hline
\end{tabular}

Source: SINAN/SEMUSA/MS, 2010-2018 - Rondolândia-MT

\section{Discussion}

American cutaneous leishmaniasis (LTA) is an infectious disease caused by protozoan species of the genera Leishmania amazonenses, Leishmania Viannia braziliensis, Leishmania Viannia guyanensis, Leishmania Viannia lainsoni, Leishmania Viannia naiffi, Leishmania Viannia shawi. The vector is 
known as straw mosquito. American tegumentary leishmaniasis is considered a neglected disease, since it affects mainly low-income populations [9].

The research is an epidemiological study with secondary data provided by the statistical sector of the municipality of Rondolândia-MT, thus, more detailed data such as patient charts and laboratory tests identifying the species diagnosed were not informed [8].

According to the Ministry of Health (BR), there are three forms of epidemiological manifestations of tegumentary leishmaniasis, being wild, occupational and leisure, and rural and peri-urban [10].

The municipality of Rondolândia-MT is located in the interior of the state of Mato Grosso located 1,182.0km from the capital Cuiabá, its territorial extension and $12,670,852 \mathrm{~km}^{2}$ composed of 3,966 inhabitants [2, 5, 10, 11].

The municipality of Rondolândia-MT presented $100 \%$ of the cases of American tegumentary leishmaniasis in the rural zone, which can be said that the type of epidemiological manifestations occurred were "wild" and "occupational and leisure", being wild "the transmission occurs in primary vegetation area and is fundamentally a zoonosis of wild animals and the occupational and leisure transmission is associated with the disorderly exploitation of the forest and the clearing of forests for the development of agricultural activities, settlement", extraction which is the main source of income of the municipality [8].

The incidence of American cutaneous leishmaniasis has been increasing in the municipality of Rondolândia-MT, presenting common symptoms such as: skin lesion in the nose, ear, upper limb and lower extremity of the notification were not informed of the locations in the notification form and thus it is not possible to quantify the location that has the most preference for the vector [8].

According to Zóia's research (1993), lesions appeared as single or multiple lesions in various places of the body, usually in more unprotected (naked) areas, such as in the arms, legs, face and neck, in the form of ulcers, very often these lesions do not have a foul odor, they are reddish and shiny $[12,13]$.

In the year 2014, the municipality of Rondolândia-MT presented $20.00 \%$ of cases $(n=8)$, all occurring in males, being $(n=7)$ in the age group of 20 to 39 years.

The incidences of the disease cases in the municipality of Rondolândia-MT were common in males, the total samples corresponded to $90.00 \%$ of the cases as observed in (Table 2). In male (men) generally transmission occur due to exposure associated with forest environments, whereas in women and children at home [14] According to Jordano [15], leishmaniasis affects $97 \%$ economically active males in the age group 25 to 34 years of age [15] It is believed that man is more susceptible to infection due to occupations / professional activities in the field and fishing $[12,13]$.

The state of mato grosso presents a total of 21,083 cases of American tegumentary leishmaniasis reported in the period from 2010 to 2018 , that is, the samples extracted from the municipality of Rondolândia-MT in relation to the state data correspond to 1.66 / 1000hab / cases [16].
The incidence of the disease in the municipality of Rondolândia-MT in relation to the population of the municipality can be considered high, since it presents 1.00 / 100habitantes / cases.

Regarding the color of the patients reported the Rondolândia-MT survey showed that the highest incidence is related to patients of brown color with $45.71 \%$ and followed by white color $40.0 \%$. According to the study by Almeida [13] conducted in the state of Acre, the incidence occurred in $70 \%$ of patients of brown color. The Valadão survey [13] carried out in the interior of the state of Rondônia states that the color that had the greatest predominance was also the brown color $[13,17]$. In relation to the data obtained by the secretary of health of mato grosso, it is confirmed that the major incidence occurs in patients of brown color corresponding to $47.67 \%$ (n $=10.052)$ [18].

Regarding lesions, $95 \%$ of the patients who were notified in the municipality of Rondolândia-MT presented a cutaneous lesion "usually manifest initially with an ulcerated skin lesion, which in turn may be unique anywhere in the body [19].

The appearance of ulcerated skin lesions usually occurs in regions such as: forearm, wrist, nape, face, wrist, ear and leg", cutaneous leishmaniasis (LC) is defined by the presence of lesions exclusively on the skin, point of inoculation of the infective promastigotes through the vector bite to any of the Leishmania species that cause the disease [20].

In the municipality of Rondolândia-MT, about $5.0 \%$ of the patients had mucosal lesions, and these cases were reported as recurrences. The sites that presented the lesions were not informed in the notification form, but all patients who started treatment within the municipality stated that they had lesions on the mouth, nose, and ear.

Cutaneous lesions are the most common symptoms of American tegumentary leishmaniasis, however, usually presented at the beginning or after one year, may present mucosal lesion. This symptomatology caused by mucosal lesion is usually caused by Leishmania Viannia braziliensis, and its preferential areas are the mouth, lips, pharynx and larynx [21].

According to the author Lessa [21] a study conducted in the city of Três Brazos-BA shows that the disease with mucosal lesions may occur within 264 months after the cutaneous lesion, however, only $7 \%$ of the patients developed the involvement of the mucosa after more than 10 years of the appearance of the cutaneous lesion.

According to the data obtained in Rondolândia-MT, 85.0\% of the patients had their diagnosis confirmed by the laboratory. There are several methods of laboratory diagnosis of American tegumentary leishmaniasis, one of the most used is the direct search of the parasite, and the intradermalimulation test, if one observes the clinical aspect presented by the disease in the suspected patient [9]. According to Kings [21] the montenegro intradermalimetre test is used to detect Leishmania infection in humans. The technique is based on a delayed hypersensitivity reaction.

With respect to the Rondolândia-Mato Grosso do Sul city survey, $15.0 \%$ of the cases had another way of confirming the 
patients' diagnosis, being the clinic / epidemiologist, where the professional has to be well aware of the incidence of the disease in the region, for which can not be confused with other diseases. When assessing the patient's skin, the professional should attend to and exclude present skin lesions, stasis, traumatic ulcers, diabetes, tropical diseases, pyoderma, sickle cell anemia, paracoccidioidomycosis, sporotrichosis, cutaneous neoplasias, chromoblastomycosis, syphilis and tuberculosis [22].

According to the Ministry of Health (BR) treatment manual, there are two types of pentavalent antimonials on the international market, being "meglumine antimoniate" and "sodium stibogluconate", the most used being meglumine antimoniate $(5 \mathrm{ml}$ vial containing $1.5 \mathrm{~g}=405 \mathrm{mg}$ of $\mathrm{Sb}+5$ ) and sodium stibogluconate is not marketed in Brazil. Administration in adult patients with meglumine antimoniate can be done intravenously (IV / EV) or intramuscular (IM) and the intravenous route is the most used because it does not present pain in the place and can be diluted in $100 \mathrm{ml}$ of $5 \%$ glycosated serum slowly infusing in up to 30 minutes, or, can be administered directly undiluted using $25 \times 7$ and $25 \times 8$ [11] gauge needles.

It is always recommended to monitor the adverse effects presented by patients, and the electrocardiogram (ECG), daily heart auscultation at the time of the administration of meglumine antimoniate is performed weekly to identify possible arrhythmias, if such effects are abusive or frequent, the medication is indicated be suspended and the medical team notified so that a second choice is then prescribed.

The reports in $10.0 \%$ of the patients who were diagnosed with American cutaneous leishmaniasis were female, and were not pregnant, therefore, and one of the recommendations of the ministries of health does not administer meglumine antimoniate as it crosses the transplacental barrier. In $5.0 \%$ of the diagnosed cases were in the age group of over 60 years of age, the health ministry advises medical professionals that it is not recommended the use of pentavalent antimonials in first choice in patients over 50 years of age who are carriers of heart disease, liver disease, nephropathy, and who are allergic to some component of the medication. Constant monitoring of the cardiac system, blood count, renal system (creatinine and urea), pancreatic system and hepatic system should be performed in all patients $[11,23]$.

The treatment performed in children should preferably be administered intravenously and slowly for at least five minutes, a maximum of three ampules per day should be infused, and dilution in $100 \mathrm{ml}$ of $5 \%$ glycosated serum should also be indicated to facilitate and avoid possible Adverse reactions. They are the most common "myalgias, arthralgia, headache, anorexia, nausea and fever".

Patients with laboratory tests such as ALT / AST, alkaline phosphatase, amylase, lipase, urea and creatinine, hemoglobin and white blood cell count should be monitored regularly. cardiac arrhythmia, auscultating daily for arrhythmias, disordered P, T, S, T waves or prolongation of the QTc interval which is the most serious and associated adverse effect of death. When any of these effects occur, it should be reported to the healthcare provider and the medication stopped immediately $[3,11,18]$.
Calculations for correct dosage of systemic use for patients with confirmed diagnosis of American tegumentary leishmaniasis should be used the example of meglumine antimoniate indicated by the ministry of health (BR), for a patient of $60 \mathrm{~kg}$; $[11,23]$.

$10 \mathrm{mg} / \mathrm{kg}$ de $\mathrm{Sb}+5 /$ dia $\times 60 \mathrm{~kg}=600 \mathrm{mg}$ de $\mathrm{Sb}+5$ dia $600 \mathrm{mg} \div 81 \mathrm{mg} \mathrm{Sb}+5=7,4 \mathrm{ml}=1,5$ ampoules $/$ day

$15 \mathrm{mg} / \mathrm{kg}$ de $\mathrm{Sb}+5 /$ dia $\times 60 \mathrm{~kg}=900 \mathrm{mg}$ de $\mathrm{Sb}+5 \mathrm{dia}$

$900 \mathrm{mg} \div 81 \mathrm{mg} \mathrm{Sb}+5=11,1 \mathrm{ml}=2$ ampoules $/$ day

$20 \mathrm{mg} / \mathrm{kg} \mathrm{de} \mathrm{Sb}+5 /$ dia $\times 60 \mathrm{~kg}=1.200 \mathrm{mg}$ de $\mathrm{Sb}+5$ dia $1.200 \mathrm{mg} \div 81 \mathrm{mg} \mathrm{Sb}+5=14,8 \mathrm{ml}=3$ ampoules $/$ day

According to the data obtained, $100 \%$ of the cases belonged to the rural area of the municipality of Rondolândia-MT, the municipality and surrounded by a lot of indigenous area with a vast unexplored woodland which is the main source of income of the municipality $[8,11,23]$.

All confirmed cases of American tegumentary leishmaniasis detected in the municipality must undergo an epidemiological investigation to identify whether it is an endemic area, or whether it is a new focus arising in the region, whether the case is autochthonous or imported, identify the characteristic of the cases and do of new cases and characterize them in their clinical or laboratory form [24-26].

\section{Conclusion}

It is concluded that the incidence of cases of American tegumentary leishmaniasis in the municipality of Rondolândia-MT has increased over the years, ie, approximately 1 case per 100 inhabitants, with an annual average of 5 cases / year of the disease. An urgent action is required by the health surveillance department of the municipality to carry out disease control, since if it continues without prevention in the municipality, this annual index may suffer a great increase over the years.

The population should follow the guidelines of the Ministry of Health for the prevention of vector-borne disease, such as: using repellents when exposed in vector-friendly environments, avoiding exposure at times of vector activity (evening and in the residences use musketeers, always keep clean around yards and grounds in order to avoid breeding grounds for vector formation, always keep trees and gardens pruned in order to reduce the shading of the ground and do not serve as favorable conditions for the vector, have adequate destination for organic garbage to avoid the approximations of marsupial-type animals and rodents (source of infection for sandflies), keep pets shelters always clean, build homes with a minimum safety distance of 400 to 500 meters of the woods.

It is incumbent upon the health secretariat through guidance in the form of lecture and illustrative pamphlets to guide the population on the incidence of leishmaniasis within the municipality, and try to somehow prevent, so that this incidence will not increase over the years. 


\section{Acknowledgements}

We thank the municipal secretary of Rondolândia-MT, especially the person in charge of the epidemiological sector of the municipality, in which we provide the data without measuring any effort.

\section{References}

[1] Ministry of Health (BR). Leishmaniose- Brasília: Ministry of Health; 2007. [quoted Aug. 21, 2018]. Available at http://bvsms.saude.gov.br/bvs/dicas/126leishmaniose.html

[2] Ministry of Health (BR). American tegumentary leishmaniasis - Brasília: Ministry of Health; 2018a. [quoted Aug. 24, 2018]. Available $\mathrm{http}: / /$ portalsinan.saude.gov.br/leishmaniose-tegumentar-ameri cana.

[3] Viana, A - How to identify and treat tegumentary leishmaniasis - Minas Gerais: 2017 - [quoted on September 25, 2018]. Available At:

$<$ https://www.tuasaude.com/leishmaniose-tegumentar/>

[4] World Health Organization: Leishmaniasis - Epidemiological Report of the Americas. Pan American Health Organization: Geneva: 2016 - [quoted on September 25, 2018]. Available at: $<$ https://www.paho.org/hq/dmdocuments/2016/2016-cha-leish -informe-epi-das-americas.pdf $>$ -

[5] Brazilian Institute of Geography and Statistics - Population of Rondolândia-MT - Rondolândia: 2017a - [access on August 15, 2018] - Available at: https://cidades.ibge.gov.br/brasil/mt/Rondolândia/panorama

[6] Ministry of Health (BR). Epidemiological Bulletin of Leishmaniasis - Brasília: Ministry of Health: 2017 b [access on September 23, 2018]. Available in:

$<\mathrm{http}$ //portalarquivos2.saude.gov.br/images/pdf/2017/fe

Fevereiro/17/Vigilancia-in-Vigilancia-in-Saude-descrip-secon d-ra-a-cor.pdf $>$

[7] Gil, ACNF. - How to design research projects. 3 ed. São Paulo SP, 2001 - [online] - [Access on August 15, 2018]. Available at: $<$ https://professores.faccat.br/.../como_elaborar_projeto_de_pe squisa_-_antonio_carlos $>$ - Atlas, 1991.

[8] Municipal health department. Epidemiological data. Health Surveillance Sector: Rondolândia: 2018.

[9] Basano, SA, Camargo, LMA. American tegumentary leishmaniasis: history, epidemiology and control perspectives. [Internet]. Monte Negro / RO; 2004. [quoted 03 nov. 2018]. Available

https://www.scielosp.org/pdf/rbepid/2004.v7n3/328-337.

[10] Ministry of Health (BR). Manual of surveillance of American tegumentary leishmaniasis. Brasília: Ministry of Health; 2017. [quoted in Dec 08. 2018]. Available at: http://bvsms.saude.gov.br/bvs/publicacoes/manual_vigilancia_ leishmaniose_tegumentar.pdf\#page $=25$

[11] Ministry of Health (BR). Manual of recommendations for diagnosis, treatment and follow-up of patients with leishmaniasis. Brasília: Ministry of Health: 2015. [quoted in Dec 09. 2018]. Available at: http://bvsms.saude.gov.br/bvs/publicacoes/manual recomenda coes_diagnostico_leishmania_hiv.pdf
[12] Zóia EM,. Palombo AE.; Pedrazzani E. S. Leishmaniasis in the municipality of Porto Ferreira - [Article] - Available at: $<$ http://www.scielo.br/pdf/reben/v49n3/v49n3a12.pdf $>$ Revista. Bras: Enferm. Brasília, v. 49, n. 3, p. 445-458, 1996.

[13] American Cutaneous Leishmaniasis: epidemiological profile in the city of Rio Branco - Acre (2007-2015) - Rio Branco: 2018 [article] - South American Journal of basic technical and technological education. ISSN: 2446-4821 v. 5 n. 1 Year 2018 p. 20-31.

[14] Brilhante, AF. - Epidemiology of American tegumentary leishmaniasis (LTA) in the city of Xapuri, State of Acre, Brazil: study on human population, domestic dogs and vectors - São Paulo: 2017 - [thesis master's degree] - [quoted on Oct 23 2018] Available: $\quad<$ file: I/I C: /Users/gleis/Downloads/AndreiaFernandesBrillanteREVISAD AsimplificadoONLINE.pdf $>$

[15] Jordano, D. - Men are most affected by leishmaniasis - São Paulo: 2015 - [online] - [quoted on Oct 23, 2018]. Available: $<$ https://noticias.band.uol.com.br/cidades/amazonas/noticias/1 00000761711/em-tefe-97-dos-casos-de-leishmaniose-foram-di agnosticados-em-homens.html > -

[16] Brazilian Institute of Geography and Statistics - Territorial area of the municipality of Rondolândia-MT - Brasília-DF, 2018b [quoted on September 24, 2018] - Available: $<$ https://cidades.ibge.gov.br/brasil/mt/Rondolândia / panorama > -

[17] Valadão, CDS.; Barcelos BI.; Goes RV. et al. Study of the occurrence of American cutaneous leishmaniasis in the municipality of Ji-Paraná, 2005-2015. Brazilian Journal of Surgery and Clinical Research, v. 16, no. 3, p. 62-66, 2016.

[18] State Department of Health - Data of American tegumentary leishmaniasis state between 2010 to 2018 - Cuiabá: 2018c [quoted on 25 Oct 2018] - Available: $<$ http://www.saude.mt.gov.br/sistemas > -

[19] Dorval, MEMC et al - Occurrence of American cutaneous leishmaniasis in the State of Mato Grosso do Sul associated with Leishmania (Leishmania) amazonensis infection. Rev. Soc. Bras. Med. Trop., Uberaba, v. 39, n. 1, p. 43-46, Feb. 2006. Available from. access on 27 Nov. 2018. http://dx.doi.org/10.1590/S0037-86822006000100008.

[20] Gontijo, B; Carvalho, MLR. - American cutaneous leishmaniasis - Belo Horizonte, MG, Brazil, 2003 - [Cited on Oct 23, 2018] - Available; $<$ http://scholar.google.com/scholar_url?url=https://www.resea rchgate.net/profile/Bernardo_Gontijo/publication/26346381_L eishmanose_Tegumentar_Americana/links/544a2ff10cf2ea654 1344034/Leishmanose-Tegumentar-Americana.pdf\&hl=en = $\mathrm{X} \&$ scisig $=$ AAGBfm29qVwRTtMgl1PzswNKE1kUocoxJg $\& \operatorname{nossl}=1 \&$ oi $=$ scholarr $>$ -

[21] Lessa et al. Mucosal leishmaniasis: clinical and epidemiological aspects. São Paulo: 2007 [review article]. Rev Bras Otorrinolaringol 2007; 73 (6): 843-7.

[22] Reis, SR, Naiff, RF, almeida-Campo, FN, Franco, AR. Intradermalimoration of Montenegro in dogs (Mammalia: Canidae) experimentally inoculated by Leishmania guyanensis and Leishmania braziliensis (Kinetoplastida: Trypanosomatidae), the main agents that cause Cutaneous Leishmaniasis in the Amazon.. vol. 38 (3) 2008: 593-596. 2018]. Available at: http://www.scielo.br/pdf/aa/v38n3/v38n3a27.pdf 
[23] Ministry of Health (BR). Manual of American tegumentary leishmaniasis. Brasília: Ministry of Health: 2010 [quoted in Dec 09. 2018]. Available at: http://bvsms.saude.gov.br/bvs/publicacoes/manual_vigilancia_ leishmaniose_tegumentar_americana.pdf

[24] Steps, VMA.; Falcão, AL.; Marchchi, MCA.; Gontijo, CMF.; Dias, ES.; Barbosa-Santos, EGO.; Gerra, H. L.; Kartz, N. Epidemiological aspects of Americam Cutaneous
Leishmaniasis in a periurban area of metropolitan region of Belo Horizonte, Minas Gerais, Brazil. Mem. Inst. Oswaldo Cruz, v. 88 (1), p. 103-110, 1993

[25] Singh S, Sivakumar R. Recent advances in the diagnosis of leishmaniasis. J Postgrad Med 2003; 49: 55-60.

[26] Montenegro J. Cutaneous reactions in leishmaniasis. Archives of Dermatology and Syphilology 1926; 13: 187. 